\title{
Glucose-6-phosphate dehydrogenase deficiency in Tunisian jaundiced neonates
}

\author{
Déficit en G6PD dans une population de nouveau-nés ictériques \\ en Tunisie
}

\author{
Rym Dabboubi ${ }^{1}$ \\ Yessine Amri ${ }^{1}$ \\ Soumaya Hamdi ${ }^{1}$ \\ Hamida Jouini ${ }^{2}$ \\ Chaima Sahli ${ }^{1}$ \\ Sondess Hadj Fredj ${ }^{1}$ \\ Kamel Ben Salem ${ }^{3}$ \\ Nour ElhoudaToumi ${ }^{2}$ \\ Taieb Messaoud ${ }^{1}$ \\ ${ }^{1}$ Biochemistry Laboratory, Bechir \\ Hamza Children's Hospital, Tunis, \\ Tunisia \\ 2 Hematology Laboratory, Bechir Hamza \\ Children's Hospital, Tunis, Tunisia \\ ${ }^{3}$ Department of Community Medicine, \\ Faculty of Medicine of Monastir, \\ University of Monastir, Tunisia
}

\begin{abstract}
Background and objectives: Glucose-6-phosphate dehydrogenase (G6PD) deficiency is the most common human enzymopathy worldwide associated with hemolysis as well as neonatal jaundice, kernicterus, and even death. The goal of this study is to determinate the prevalence of G6PD deficiency in icteric neonates and to investigate its biochemical, hematological and molecular characteristics. Patients and methods: This cross sectional study was carried out on 154 icteric newborns admitted to the Bechir Hamza Children's Hospital in Tunisia. Laboratory evaluations included complete blood count, total serum bilirubin level (TSB), and erythrocyte G6PD activity. The G6PD activity was determined using a quantitative assay, which allowed us to divide the total population into two groups: normal and deficient population. The common G6PD Tunisian mutations (GdA - and GdMed) were determined using the amplification refractory mutation system (ARMS-PCR) method. Results: The prevalence of G6PD deficiency among total population (154 icteric newborns) was $18.83 \%$. Male neonates showed a higher incidence of G6PD deficiency of $11.03 \%$ compared to females $(7.79 \%)$. There was no statistical difference between the two groups (normal and deficient), in relation to the sex, peak TSB level, age at peak TSB, hemoglobin level, and hematocrit. However, there was a significant difference in gestational age. In the deficient group, $48.28 \%$ neonates presented the peak TSB level between 3 to 7 days and 55\% of the cases show a peak TSB level greater than $250 \mu \mathrm{mol} / \mathrm{L}$. The G6PD G202A variant was found in $41.37 \%$ of cases. Conclusion: This study shows a higher prevalence of G6PD deficiency in icteric newborns of Tunisia (18.83\%). This emphasizes the necessity of neonatal screening for G6PD deficiency to prevent the exposure of these newborns to known hemolytic agents and, subsequently, to prevent kernicterus or other serious complications.
\end{abstract}

Key words: G6PD deficiency, neonate, jaundice, mutations

Résumé. Le déficit en glucose-6-phosphate déshydrogénase (G6PD) est l'anomalie enzymatique la plus répandue dans le monde. Chez le nouveauné, il peut être responsable d'hyperbilirubinémie sévère parfois compliquée d'ictère nucléaire. Le but de cette étude est de déterminer la prévalence du déficit en G6PD chez les nouveau-nés ictériques et d'étudier ses caractéristiques biochimiques, hématologiques et moléculaires. Matériels et méthodes : Une étude descriptive transversale a été conduite à l'hôpital d'enfants Béchir Hamza de Tunis. Cette étude a porté sur 154 nouveau-nés ictériques. Tous les malades ont bénéficié d'un hémogramme et d'un dosage de la bilirubinémie totale. La détermination de l'activité enzymatique de la G6PD a été réalisée par la méthode spectrophotométrique, ce qui nous a permis de diviser la population totale en deux groupes : normale et déficitaire. Une étude moléculaire cherchant les mutations les plus fréquentes en Tunisie responsables du déficit 
en G6PD a été réalisée par la technique PCR/ARMS chez les nouveau-nés ictériques déficitaires. Résultats : La prévalence du déficit en G6PD dans la population totale est de $18,83 \%$. La fréquence du déficit est largement plus élevée chez les nouveau-nés de sexe masculin $(11,03 \%)$ que celle de sexe féminin $(7,79 \%)$. Nous n'avons pas trouvé de différence statistiquement significative entre les paramètres hématologiques et les concentrations de la TSB dans les deux groupes des nouveau-nés : déficitaires et indemnes de cette pathologie. Par contre une différence statistiquement significative a été observée dans les deux groupes concernant l'âge gestationnel ; 48,28 \% des nouveau-nés ayant un déficit en G6PD ont présenté un ictère néonatal entre le $3^{\mathrm{e}}$ et $7^{\mathrm{e}}$ jour de vie et $55 \%$ de ces déficitaires avaient un pic TSB $\geq 250 \mu \mathrm{mol} / \mathrm{L}$. L'étude moléculaire a montré que la mutation africaine G6PD G202A était prédominante dans 41,37 \% des cas. Conclusion : Notre étude a montré une prévalence élevée du déficit en G6PD en Tunisie chez les nouveau-nés ictériques (18,83 $\%)$. Ainsi, le dépistage systématique de ce déficit est fortement recommandé afin d'empêcher l'exposition de ces nouveau-nés à des agents hémolytiques connus et, par la suite, prévenir l'ictère nucléaire ou autres complications graves.

Mots clés : déficit en G6PD, nouveau-né, ictère, mutations

Glucose-6-phosphate dehydrogenase (G6PD) deficiency (OMIM 305900) is the most common human enzymopathy worldwide, affecting approximately 420 million people [1].

G6PD is a key enzyme in the pentose monophosphate shunt. It catalyses the reduction of nicotinamide adenine dinucleotide phosphate (NADP+) to nicotinamide adenine dinucleotide phosphate (NADPH), essential for the reduction of oxidized glutathione (GSSG) to reduced glutathione (GSH). Subsequently it plays a critical role in protecting red blood cell against oxidative agents [2].

G6PD deficiency may present with severe clinical manifestations ranging from neonatal jaundice to severe hemolytic episodes to an extreme hyperbilirubinemia leading to kernicterus. More than $65 \%$ of healthy newborns develop jaundice after $24 \mathrm{~h}$ of life. The association between this manifestation and G6PD deficiency in the neonatal period is well recognized, and could be the cause of an irreversible neurologic damage [3].

The incidence of G6PD deficiency in jaundiced newborns ranges from 3.5 to $40 \%$ [4]. Tunisia was classified by the WHO among the countries moderately affected by this affection with a frequency of 4\% [5]. However, no national program involved against complications of severe hyperbilirubinemia and kernicterus jaundiced neonates.

The clinical phenotype is a result of an interaction between molecular mutations, and other factors. The G6PD gene is located in the long arm of chromosome X (Xq28), with 13 exons and 12 introns [6]. Thirteen exonic mutations and 7 intronic variations have been identified in our country with the predominance of G202A (Gd A- or Matera) and C563T (Gd B- or Mediterranean) mutations [7].

To date, there is no study undertaken to ascertain the prevalence of G6PD deficiency in Tunisian jaundiced neonates. Therefore, the goal of this study is to determinate the prevalence of G6PD deficiency in neonates admitted with clinically evident jaundice and to investigate its biochemical, hematological and molecular characteristics.

\section{Materials and methods}

This study was carried out in accordance with the principles of the Declaration of Helsinki developed by the World Medical Association and approved by the Human Ethics committee of Bechir Hamza Children's Hospital.

\section{Study design}

A cross sectional study was carried out on 154 cases of neonatal jaundice from April 2018 to June 2018 at Bechir Hamza Children's Hospital in Tunisia.

All term and preterm neonates up to thirteen-day of age admitted with clinically evident jaundice were included in the study. Physical examination was performed. The sex, the age of peak bilirubin, maximum bilirubin level were recorded. Laboratory evaluations included complete blood count, total serum bilirubin level (TSB), and erythrocyte G6PD level. 


\section{Quantitative determination of G6PD activity}

Two $\mathrm{mL}$ blood was collected from each patient in a tube containing EDTA as an anticoagulant for quantitative G6PD testing and molecular analysis. The erythrocyte G6PD activity was determined by an enzymatic colorimetric assay. Quantitative testing for G6PD was performed using a commercial kit (G6P-DH; catalog no. 17.005; Sentinel Diagnostics, Milan, Italy). Biochemical parameters were measured on blood collected in lithium heparin anticoagulant.

The results were expressed in IU/g of hemoglobin. The average of normal value and standard deviation of G6PD enzymatic activity in normal neonates in our laboratory was $12.23 \pm 3.1 \mathrm{IU} / \mathrm{g} \mathrm{Hb}$. Any neonate with G6PD activity lower than $60 \%$ of normal activity (7.0 IU/g Hb) was considered as being G6PD deficient.

\section{Hematological measurement}

A complete haemogram was done by standard procedures on an automated cell counter (Beckman LH750 ${ }^{\mathrm{TM}}$ Hematology analyzer Beckman, Miami, FL, USA).

\section{Biochemical analysis}

The total serum bilirubin level (TSB) was measured using colorimetric assays on the Cobas 501 (Roche Diagnostics International Ltd, Rotkreuz, Switzerland).

\section{Molecular studies}

Genomic DNA was extracted from peripheral blood leukocytes using commercially available Invitrogen Genomic DNA Mini kit (PureLinkTM, USA) following the manufacturer's instructions, and was stored at $4^{\circ} \mathrm{C}$ until used. The identification of the common G6PD Tunisian mutations (GdA - and GdMed) was established using the amplification refractory mutation system (ARMS-PCR) as previously described [7].

\section{Statistical analysis}

The collected data were processed using SPSS version 20.0 (SPSS, Chicago, IL). The Kolmogorov-Smirnov test was used to confirm normal distribution of continuous variables. Data were presented as mean \pm standard deviation and mean comparisons were performed by the Student t-test for two independent samples. In case of no normal distribution, data were expressed as medians [min-max] and were compared using Mann-Whitney U test. Categorical variables were presented as numbers or group percentages and comparison between groups was performed using the chi-square test ( $\chi 2$ test). $\mathrm{P}$ value $\leq 0.05$ was considered as statistically significant.

\section{Results}

\section{Demographics and laboratory evaluation}

In this study, total 154 neonates having jaundice were selected at children Hospital during period of three months between April to June 2018.

Among the 154 neonates, 86 (56.49\%) were males and 68 $(43.51 \%)$ were females. Of these, $111(72.07 \%)$ were early neonates (aged up to 7 days) and $43(27.93 \%)$ were late neonates (aged 8 to 30 days).

One hundred twenty seven neonates $(82.5 \%)$ in this study were full term (GA (gestationnel age): 37-40 wk (week)), $26(16.9 \%)$ were preterm $(\mathrm{GA}<37 \mathrm{wk})$, and one $(0.6 \%)$ was post term (GA $>40 \mathrm{wk}$ ) with a mean gestational age of $37.51 \pm 2.48 \mathrm{wk}$.

The prevalence of G6PD deficiency among total population (154 neonates) was $18.83 \%$ (29 deficients out of 154). Male neonates showed a higher incidence of G6PD deficiency of $11.03 \%$ (17/154) compared to females who had an incidence of $7.79 \%(12 / 154)$.

Sex distribution in G6PD-normal group was 55 females (35.71\%) and 70 males (64.29\%). We noted a no significant difference between male and female in G6PD-normal groups $(\mathrm{p}=0.85)$.

In the deficient group, the G6PD mean was $3.34 \pm 1.87$ $\mathrm{UI} / \mathrm{g} \mathrm{Hb}$. In males, the value was significantly lower (2.66 $\pm 1.85 \mathrm{UI} / \mathrm{g} \mathrm{Hb})$ than in females $(4.30 \pm 1.48 \mathrm{UI} / \mathrm{g} \mathrm{Hb})(\mathrm{p}$ $=0.017$ ) (table 1).

There were no statistical differences in the characteristics between the two groups (normal and deficient), in relation to the sex, peak TSB level, age at peak TSB, hemoglobin (Hb) level, platelets, MCV, RBC and hematocrit. However, there was a significant difference in gestational age and the G6PD activity (table 2).

In the deficient group, the age at peak TSB level was less than 3 days in 6 cases $(20.69 \%)$, whereas, 14 (48.28\%) neonates presented the peak between 3 to 7 days, and 9 (31.03\%) after 7 days. The peak TSB level in the deficient groups was found greater than $250 \mu \mathrm{mol} / \mathrm{L}$ in $8(55 \%)$ cases. Among these later, 3 had a level greater than 350 and two exceeding $450 \mathrm{pmol} / \mathrm{L}$.

\section{Molecular analysis and G6PD assay}

G6PD mutations (G6PD G202A (Gd A- or Matera) and C563T (Gd B- or Mediterranean)) were analyzed in only 24 deficient's newborns since 5 samples were not fully analyzed because of insufficient quantity of DNA. G202A variant was detected in $12(41.37 \%)$ newborns and G6PD C563T was detected in one patient in the heterozygous state $(3.44 \%)$ with G6PD enzymatic activity: $1.5 \mathrm{UI} / \mathrm{gHb}$. Among the G202A G6PD deficient neonates, 8 were male hemizygotes, 3 were female heterozygotes 
and one female homozygote. The genotype of 11(37.93\%) newborns remained uncharacterized. The later include newborns with G6PD G202A mutation showed markedly low levels of G6PD enzyme activity (mean $\pm \mathrm{SD} ; 3.36 \pm 2.15$ $\mathrm{UI} / \mathrm{gHb}$ ) compared toG6PD normal newborns (mean $\pm \mathrm{SD}$; $13.92 \pm 4.82, \mathrm{p}<0.001)$.

\section{Discussion}

In this study, the incidence of G6PD enzyme deficiency in Tunisian jaundiced neonates was found to be $18.83 \%$. Our results are comparable with the findings of a similar Saudi Arabian study, with an incidence of $18.4 \%$ [8]. In contrast, some studies showed a higher incidence of G6PD deficiency as reported in Basrah (51\%) [9] or a lower incidence which was around 9\% in Iranian study [10]. The incidence of G6PD deficiency was determined previously in general Tunisian population (4.4\%) [5].

This variability of the incidence of this disease in different geographical locations worldwide could be explained by a combination of genetic and environmental risk factors.

Neonatal jaundice is a major cause of admission to the neonatology unit. A previous study identified G6PD deficiency in up to $62 \%$ of newborns admitted from home with severe neonatal jaundice and kernicterus [11]. The severity of jaundice depends on the underlying etiological factors. In the current study, we found no statistical difference between G6PD-deficient and normal neonates in the sex, time and the peak TSB level, hematocrit level, and $\mathrm{Hb}$ level, except for gestational age. A similar study carried out on 376 newborns showed no statistical differences in the $\mathrm{Hb}$ level, reticulocyte count and the peak TSB level [12].

G6PD deficiency is an $\mathrm{X}$-linked disorder, transmitted by mothers affecting mainly boys. Affected girls are very often in partial deficit [3]. This is confirmed by our results which showed a higher frequency in male newborns $15 \%$ (17/154) compared to those of the females $7 \%(12 / 154)$. This male preponderance of G6PD deficiency is a well documented fact in a Tunisian study [14]. In the deficient group, the G6PD mean value was significantly lower in males (2.66 $\pm 1.85 \mathrm{U} / \mathrm{g} \mathrm{Hb})$ than in females $(4.30 \pm 1.48 \mathrm{U} / \mathrm{g} \mathrm{Hb})(\mathrm{p}$ $=0.017)$. The expression is greater in males compared to female as they have only one $\mathrm{X}$-chromosome without ability to suppress expression of the abnormal gene. The heterozygous females bearing one defective gene and one normal gene may express normal, intermediate, or low G6PD activity [15]. Therefore, the inclusion of girls in screening for G6PD deficiency is recommended in most neonatal screening programs for G6PD challenge.

In the present study, $48.28 \%$ of the neonates with G6PD deficiency presented with neonatal jaundice between $3^{\text {rd }}$ and 7 day of life. These findings are consistent with the 
Table 2. Demographic and clinical data in 29 G6PD-deficient and 125 G6PD-normal neonates with neonatal jaundice.

\begin{tabular}{|llll|}
\hline Variable (unit) & $\begin{array}{l}\text { Normal }(\mathbf{n}=\mathbf{1 2 5}) \\
\text { Mean } \pm \text { SD }\end{array}$ & $\begin{array}{l}\text { Deficient }(\mathbf{n}=\mathbf{2 9}) \\
\text { Mean } \pm \text { SD }\end{array}$ & p-value \\
\hline Gestational age $(w k)$ & $37.25 \pm 2.61$ & $38.62 \pm 1.32$ & $0.027^{*}$ \\
\hline RBCs $\left(\times 10^{12} / \mathrm{L}\right)$ & $4.10 \pm 0.89$ & $3.81 \pm 0.83$ & $0.91^{*}$ \\
\hline $\mathrm{Hb}(\mathrm{g} / \mathrm{dL})$ & $13.62 \pm 2.67$ & $13.12 \pm 2.94$ & $0.53^{*}$ \\
\hline $\mathrm{PLQ}\left(10^{3} / \mathrm{ML}\right)$ & $291.50 \pm 126.40$ & $310.90 \pm 167.30$ & $0.68^{*}$ \\
\hline $\mathrm{MCV}(\mathrm{fL})$ & $99.28 \pm 12.70$ & $100.46 \pm 4.76$ & $0.28^{*}$ \\
\hline Hct $(\%)$ & $39.74 \pm 7.71$ & $38.46 \pm 8.78$ & $0.57^{*}$ \\
\hline Peak TSB level $(\mu \mathrm{mol} / \mathrm{L})$ & $218.56 \pm 80.14$ & $220.89 \pm 96.92$ & $0.65^{*}$ \\
\hline Age at peak TSB [days; min-max] & $5[1-30]$ & $4.5[1-30]$ & $0.96^{* *}$ \\
\hline G6PD $(\mathrm{U} / \mathrm{gHb})$ & $13.92 \pm 4.82$ & $3.34 \pm 1.87$ & $<0.001^{*}$ \\
\hline
\end{tabular}

RBCs: red blood cells; Hb: hemoglobin; HCT: hematocrit; MCV: mean corpuscular volume; PLQ: platelet; SD: standard deviation; G6PD: glucose-6-phosphate dehydrogenase; TSB: total serum bilirubin. *Student $t$ test. ${ }^{* *}$ Mann-Whitney $\mathrm{U}$ test.

notion that G6PD deficiency causes late-onset jaundice. The same result was found by similar studies [16].

Mean peak TSB level in G6PD deficient neonates (220.89 $\pm 96.92 \mu \mathrm{mol} / \mathrm{L})$ is slightly higher than G6PD normal neonates $(218.56 \pm 80.14 \mu \mathrm{mol} / \mathrm{L})$ with no statistically significant difference $(\mathrm{p}=0.65)$. This result is corroborating with the findings of an Indian study [17]. However, a study conducted by Sinha et al. showed a significant statistical difference between G6PD deficient and non-G6PD deficient group in terms of TSB levels [18]. In other study, a significant difference in the prevalence of hyperbilirubinemia between G6PD deficient and G6PD normal neonates was found only in males, not in females [19].

These variations can be explained by the fact that variants of G6PD enzyme present in different ethnic groups may be different thereby causing varying degree of severity among those affected by the deficiency states. Furthermore, these variations can be related to the degree of G6PD mosaicism in G6PD deficient female.

In the G6PD-deficient neonates group, 55\% are at risk of severe hyperbilirubinemia with peak TSB level reaching $250 \mu \mathrm{mol} / \mathrm{L}$ or more. Similar findings were reported in a study showed that $52 \%$ patients had a peak TSB level in the range of 250-350 $\mu \mathrm{mol} / \mathrm{L}$ [20]. This finding should be underlined to state the importance of early screening programs for G6PD-deficiency which could cause severe neonatal morbidity.

Jaundice in G6PD-deficient individuals has often been ascribed to the inability of the liver to adequately conjugate bilirubin. This clinical manifestation depends on a variety of interactions between the G6PD-deficient states, genes encoding bilirubin conjugation, and environmental influences [21].

Severe clinical phenotypes have been reported in carriers of somes mutations [22]. In this study, the two commonest alleles causing Tunisian G6PD deficiency in at least $44.81 \%$ of the cases were G6PD Matera (GdA-202A/376G) $(41.37 \%)$ and G6PDMed $(563 \mathrm{C} \rightarrow \mathrm{T})(3.44 \%)$. The finding of these two common alleles in the Tunisian is in concordance with many other reported studies in Tunisian population [7].

A study in an African American neonates, a subgroup of G6PD-deficient newborns mainly of G6PDG202A molecular background showed a higher incidence of hyperbilirubinemia and a greater requirement for phototherapy [23].

\section{Conclusion}

Neonatal jaundice is one of the most common problems and requires hospital admission for investigation and treatment. G6PD deficiency has been considered as one of 10 most important etiologies of non-hemolytic neonatal jaundice. In a population with a middle prevalence rate, like Tunisia, early detection of G6PD enzyme deficiency by neonatal screening is desirable to take appropriate measures to prevent the complications of hemolysis and jaundice in order to reduce the mortality or morbidity of neonatal jaundice.

Conflict of interest: none of the authors has any conflict of interest to disclose concerning this article.

\section{References}

1. Minucci A, Giardina B, Zuppi C, Capoluongo E. Glucose-6-phosphate dehydrogenase laboratory assay: how, when, and why? IUBMB Life $2009 ; 61: 27-34$.

2. Dorche C. Pathologie des enzymes de la glycolyse érythrocytaire. Rev Fr Lab 2000 ; 2000(324) : 37-43. 
3. Cunningham AD, Hwang S, Mochly-Rosen D. Glucose-6-phosphate dehydrogenase deficiency and the need for a novel treatment to prevent kernicterus. Clin Perinatol 2016 ; 43(2) : 341-54.

4. Marzban A, Mosavinasab N. Correlation between hemolysis and jaundice in glucose 6-phosphate dehydrogenase deficient neonates. Acta Med Iran $2009 ; 47(5): 379-82$.

5. Guellouz N, Ben Mansour I, Ouederni M, Jabnoun S, Kacem S, Mokrani C, et al. Neonatal screening of G6PD deficiency in Tunisia. Arch Inst Pasteur Tunis 2010;87:69-76.

6. Martini G, Toniolo D, Vulliamy T, Luzzatto L, Dono R, Viglietto G, et al. Structural analysis of the $\mathrm{X}$-linked gene encoding human glucose 6-phosphate dehydrogenase. EMBO J 1986; 5 : 1849-55.

7. Haloui S, Laouini N, Sahli CA, Dabboubi R, Becher M, Jouini L, et al. Molecular identification of Gd A- and Gd B- G6PD deficient variants by ARMS-PCR in a Tunisian population. Ann Biol Clin 2016; 74 : 219-26.

8. Yaish HM, Niazi GA, Al-Shaalan M, Khan S, Ahmed GS. Increased incidence of hyperbilirubinaemia in unchallenged glucose-6-phosphate dehydrogenase deficiency in term Saudi newborns. Ann Trop Paediatr $1991 ; 11: 259-66$.

9. Al-Naama LM, Al-Sadoon IA, Al-Naama MM. Neonatal jaundice and glucose-6-phosphate dehydrogenase deficiency in Basrah. Ann Trop Pediatr 1987 ; 9 : 134-8.

10. Karimi M, Martinez di Montemuros F, Danielli MG, Farjadian S, Afrasiabi A, Fiorelli G, et al. Molecular characterization of glucose6-phosphate dehydrogenase deficiency in the Fars province of Iran. Hematological 2003 ; 88 : 346-7.

11. Slusher TM, Vreman HJ, McLaren DW, Lewison LJ, Brown AK, Stevenson DK. Glucose-6-phosphate dehydrogenase deficiency and carboxyhemoglobin concentrations associated with bilirubin-related morbidity and death in Nigerian infants. $J$ Pediatr 1995;126: 102-8.

12. Koosha A, Rafizadeh B. Evaluation of neonatal indirect hyperbilirubinaemia at Zanjan Province of Iran in 2001-2003: prevalence of glucose-6-phosphate dehydrogenase deficiency. Singapore Med J $2007 ; 48: 424-8$.
13. Atay E, Bozaykut A, Ipek IO. Glucose-6-phosphate dehydrogenase deficiency in neonatal indirect hyperbilirubinemia. J Trop Pediatr $2006 ; 52: 56-8$.

14. Laouini N, Bibi A, Ammar H, Kazdaghli K, Ouali F, Othmani R, et al. Glucose-6-phosphate dehydrogenase deficiency in Tunisia: molecular data and phenotype-genotype association. Mol Biol Rep 2013 ; 40 : 851-6.

15. Lyon MF. X-chromosome inactivation and human genetic disease. Acta Paediatr Suppl 2002 ; 91 : 107-12.

16. Ainoon O, Yu YH, Boo NY, Cheong SK, Hamidah HN, Lim JH. Complete molecular characterisation of glucose-6-phosphate dehydrogenase (G6PD) deficiency in a group of Malaysian Chinese neonates. Malaysian J Pathol 2004 ; 26 : 89-98.

17. Verma M, Singla D, Crowell SB. G6PD deficiency in neonates: a prospective study. Indian J Pediatr 1990; 57 : 385-8.

18. Sinha R, Sachendra B, Sabid Syed V, Nair L, John BM. To study the prevalence of glucose 6 phosphate dehydrogenase (G6PD) deficiency in neonates with neonatal hyperbilirubinemia and to compare the course of the neonatal jaundice in deficient versus non deficient neonates. $J$ Clin Neonatol $2017 ; 6: 71-4$

19. Huang CS, Hung KL, Huang MJ, Li YC, Liu TH, Tang TK. Neonatal jaundice and molecular mutations in glucose-6-phosphate dehydrogenase deficient newborn infants. Am J Hematol 1996; 51 : 19-25.

20. Kuruvilla KA, Sakumar ST, Jana AK. Glucose-6-phosphate dehydrogenase deficiency in neonatal hyper-bilirubinemia in a south Indian referral hospital. Indian Pediatr 1998; 35 : 52-5.

21. Kaplan M, Hammerman C. Glucose-6-phosphate dehydrogenase deficiency and severe neonatal hyperbilirubinemia: a complexity of interactions between genes and environment. Semin Fetal Neonatal Med $2010 ; 15: 148-56$.

22. Pietrapertosa A, Palma A, Campanale D, Delios G, Vitucci A, Tannoia N. Genotype and phenotype correlation in glucose-6-phosphate dehydrogenase deficiency. Haematologica $2001 ; 86$ : 30-5.

23. Kaplan M, Herschel M, Hammerman C, Hoyer JD, Stevenson DK. Hyperbilirubinemia among African American, glucose-6-phosphate dehydrogenase-deficient neonates. Pediatrics Aug 2004 ; 114 : 213-9. 